University of Nebraska - Lincoln

DigitalCommons@University of Nebraska - Lincoln

Faculty Publications, Department of Psychology

Psychology, Department of

January 1994

\title{
A Multiplicative Model of the Dispositional Antecedents of a Prosocial Behavior: Predicting More of the People More of the Time
}

George Knight

Arizona State University, george.knight@asu.edu

Lora G. Johnson

Arizona State University

Gustavo Carlo

University of Nebraska-Lincoln, carlog@missouri.edu

Nancy Eisenberg

Arizona State University, nancy.eisenberg@asu.edu

Follow this and additional works at: https://digitalcommons.unl.edu/psychfacpub

Part of the Psychiatry and Psychology Commons

Knight, George; Johnson, Lora G.; Carlo, Gustavo; and Eisenberg, Nancy, "A Multiplicative Model of the Dispositional Antecedents of a Prosocial Behavior: Predicting More of the People More of the Time" (1994). Faculty Publications, Department of Psychology. 165.

https://digitalcommons.unl.edu/psychfacpub/165

This Article is brought to you for free and open access by the Psychology, Department of at DigitalCommons@University of Nebraska - Lincoln. It has been accepted for inclusion in Faculty Publications, Department of Psychology by an authorized administrator of DigitalCommons@University of Nebraska - Lincoln. 
Published in Journal of Personality and Social Psychology 66:1 (1994), pp. 178-183. Copyright (C) 1994 by the American Psychological Association, Inc. "This article may not exactly replicate the final version published in the APA journal. It is not the copy of record." http://www.apa.org/journals/psp/

\title{
A Multiplicative Model of the Dispositional Antecedents of a Prosocial Behavior: Predicting More of the People More of the Time
}

\author{
George P. Knight, Lora G. Johnson, Gustavo Carlo, and Nancy Eisenberg \\ Department of Psychology, Arizona State University
}

\begin{abstract}
Researchers have demonstrated that individual differences in prosocial behavior may be a function of dispositional or person variables. However, the observed empirical relations have been relatively modest, perhaps because researchers have most often examined simple additive or single predictor models. The present investigation examined a multiplicative model of the relation of dispositional variables to a prosocial behavior. Eighty-six children between 6 and 9 years old completed a monetary donation task and measures of the general tendency to understand and reason about the affective state of others, to be sympathetic, and to understand the units and value of money. As expected, children who scored high in affective reasoning, sympathy, and money knowledge donated considerably more than children who scored low in any of these dispositional variables.
\end{abstract}

Although researchers have demonstrated empirical relations among dispositional variables and prosocial behavior, a number of authors have tried to explicate the relatively modest magnitude and inconsistencies of these relations (e.g., Eisenberg, 1986; Staub, 1978). One possible explanation for the relatively modest relations is that a number of dispositional variables may be related to a given prosocial behavior and that these relations may be multiplicative in nature. That is, the probability of enactment of a specific prosocial behavior may be dependent on several dispositional characteristics operating in conjunction. Some researchers (e.g., Staub, 1978) have suggested that the prediction of prosocial behaviors, as well as other behaviors, could be enhanced by the use of multiple dispositional predictors. However, both the interactive relations of multiple dispositional predictors and the interaction of emerging developmental dispositions with more stable dispositional predictors have rarely been investigated. The present investigation was designed to examine the multiplicative relations of several dispositional variables to a prosocial behavior.

If a given prosocial behavior has multiple dispositional antecedents that relate to behavior in a multiplicative manner, then the past research may have underestimated the magnitude of these relations and the potential causal importance of personality by examining single predictor or simple additive models. More specifically, the absence of a subset of requisite dispositional qualities may substantially reduce the likelihood of a given prosocial behavior, and this reduction could be more than would be expected by a simple additive model.

Yet another possible explanation for the relatively modest relations just noted may have to do with the selection of the specific dispo- sitional variables that have been related to specific prosocial behaviors. Different prosocial behaviors may have different sets of dispositional antecedents, and the selection of dispositional predictors may need to be based on a task analysis of the specific behavioral criterion. For example, consistent with the suggestions of Snyder and Ickes (1985), the Person $\times$ Situation interaction may influence behavior by "pulling for" or creating situation-specific dispositional correlates. Thus, the situation in which the prosocial behavior occurs and specific features of the behavior may determine the specific dispositional variables that are related to a given prosocial behavior.

The dispositional variables assessed in this investigation were selected on the basis of a task analysis of the specific opportunity for prosocial behavior. Task analysis is a technique often used by cognitive psychologists to identify and describe the cognitive and information-processing demands of a specific behavioral task (see Chao, Knight, \& Dubro, 1986, for an example). Because the present prosocial behavior consisted of the opportunity for children to donate money to needy others who were in a situation that presented mixed and incongruent affective cues, the most relevant dispositional variables identified in the task analysis were affective reasoning (or affective reconciliations, the tendency to understand and reconcile an ambiguous affective context), sympathy (feelings of concern and sorrow for another), and money knowledge (understanding the units and value of specific denominations of money).

There is considerable evidence of individual differences in affective reasoning (e.g., Carlo, Knight, Eisenberg, \& Rotenberg, 1991), sympathy (or empathic concern; see Davis, 1983), and money knowledge (e.g., Berti \& Bombi, 1981) among children. Furthermore, as theoretically expected, both affective reasoning and sympa-

This research was supported by funds from the Office of the Vice President of Research at Arizona State University to George P. Knight, the National Science Foundation (BNS-8917866) to Gustavo Carlo and Nancy Eisenberg, and the National Science Foundation (BNS-8807784 and DBS-9208375) and the National Institute of Mental Health (KO2MH00903-01) to Nancy Eisenberg. We thank Recreation Coordinator Julie Munson of the Phoenix Parks and Recreations Programs and the participating recreation leaders, field staff, and children. We also express appreciation to Sandy Braver, Deanna Gardner, Steve Johnson, and Steve Neuberg for comments on earlier manuscripts. 
thy have been positively related to prosocial behavior (e.g., Carlo et al., 1991; Eisenberg, 1986; Underwood \& Moore, 1982). However, consistent with the general literature relating dispositional variables to behavior, the relations of these variables to prosocial behaviors have been relatively modest. For example, in a meta-analytic study, Eisenberg and Miller (1987) found that questionnaire indices of dispositional sympathy or empathy accounted for approximately $3 \%$ of the variance in prosocial behavior. In addition, there is an emerging body of evidence of covariation between prosocial behavior and situation-demanded dispositional variables (e.g., Brady, Newcomb, \& Hartup, 1983; Chao et al., 1986; Knight, Bohlmeyer, Stewart, \& Harris, 1993).

In the present investigation it was expected that a child may donate money to needy others in an affectively ambiguous situation if the child (a) tends to understand and reason about the affective plight of others, (b) is generally sympathetic when aware of another's negative situation, and (c) understands the units and value of denominations of money. However, the absence of anyone or more of these characteristics may substantially reduce donating, and this reduction may be larger than would be expected on the basis of a simple additive model. That is, it was expected that although each of these dispositional variables may be separately related to donation, the multiplicative (i.e., moderational) predictors (particularly the three-way interaction) should account for a substantial proportion of the variance in donation above and beyond the main effect predictors.

\section{Method}

\section{Subjects}

The subjects were 86 children ( 43 girls and 43 boys) between 6 years, 0 months and 8 years, 11 months of age $(M=90.8$ months, $S D=$ 11.0 months). The participating girls and boys were all children from a summer recreation camp who returned a signed parental consent form. These children were relatively evenly distributed across the age range.

\section{Measures}

Affective reasoning. The affective reasoning task (adapted from Iannotti, 1978) consisted of eight randomly ordered black-and-white photographs mounted on paper (sex of the child in the picture was matched with the sex of the participant) and corresponding stories. There were five congruent stories (two sad and three happy) in which the facial expression and the situational cues in the story were consistent (e.g., a child smiling while looking at his or her birthday cake). In addition, there were three incongruent stories in which the facial expression and the situational cues were conflicting (e.g., a child holding a tray of cookies while frowning). The incongruent stimuli included two stories with a happy face in a sad situation and one with a sad face in a happy situation.

Children were asked to identify the affect of the character in each story by pointing to a face on a facial choice sheet (one sheet for each sex) that displayed line drawings of three randomly ordered sets of facial expressions. The three sets of facial expressions included a total of five faces: a pair of happy-very happy faces, a pair of sad-very sad faces, and a neutral face. Before presenting the stories and after each story, the experimenter pointed to each of the faces on the facial choice sheet and labeled each one until it was clear the child understood the faces.

For each story, the picture depicting the events in the short story was covered with a sheet of paper as the experimenter read the story. The picture was revealed at a prompt (as designed by Iannotti, 1978) dur- ing the middle of the story. The children were then asked to indicate how the character in the story felt and how they knew the protagonist felt that way. The children were required to indicate their choice of emotion on the facial choice sheet by pointing, even if they verbalized the emotions to the first two questions.

The affective reasoning score (see Carlo et al., 1991) was the number of times the child's responses to an incongruent picture story indicated any acknowledgment of, and compromise or rationalization of, the incongruent cues (e.g., "He's sad because his mom didn't make the kind of cookies he liked most" in response to the picture of the frowning child holding a tray of cookies). The coding of this relatively advanced affective reasoning was not appropriate from the congruent picture stories because the facial and situational cues were compatible and did not require reconciliation in these stories. ${ }^{1}$ Exact interrater agreement on $28 \%$ of the cases coded by two independent judges was $93 \%$ for affective reasoning. Scores on this affective reasoning measure were related to a prosocial behavior in previous research (Carlo et al., 1991).

Sympathy. The sympathy measure consisted of two of the three items used by Eisenberg, Fabes, Schaller, Carlo, and Miller (1991), which were adapted from the Davis (1983) Empathic Concern (sympathy) Scale: "I often feel sorry for other children who are sad or in trouble" and "When I see someone being picked on, I feel kind of sorry for them." ${ }^{2}$ Children responded on a 5-point scale with anchors (marked by stacks of checkers of varying heights) ranging from not at all like me to always like me. Each item was scored from 1 (least sympathy) to 5 (most sympathy) and summed across the two items to form the sympathy index. Cronbach's alpha reliability for this two-item scale was .60. Among children in the same age range as the present sample, Eisenberg et al. (1991) found, as expected, that girls scored higher than boys on the three-item index of sympathy and that this index correlated with other dispositional (e.g., the Bryant Empathy Scale [1982]) and state indexes of sympathy or empathy (physiological reactions and self-reports).

Money knowledge. The knowledge about money measure consisted of nine items selected from teacher workbooks designed for instructing children in this age range. Each question was accompanied by a pictorial display appropriate to the question being asked. For example, one item included a picture of a $\$ 1$ bill and 10 quarters, and the child was asked to "color the coins to make one dollar." The questions covered topics such as "Which of the two pictures has more money in it?" "How many quarters make a dollar?" "Can you buy this" object with the available money in the display, and "Which item costs more?" These items were designed to assess children's general facility with the units and values of various bills and coins (similar to Berti \& Bombi, 1981). Each item on the knowledge of money scale was scored as 1 if correct and 0 if incorrect and was summed across items to create the money knowledge index. Cronbach's alpha reliability for this nine-item scale was .65 .

\section{Procedure}

Children were individually escorted to a quiet room by a female experimenter. The experimenter was unaware of the scoring of the affective reasoning measure and was trained to follow a standardized script; therefore, the expected three-way interaction likely could not be produced

${ }^{1}$ An affective attribution score (i.e., number of correct affective labels in congruent picture stories) was not used in the analyses because of very little variability (i.e., over $99 \%$ were correct responses).

${ }^{2}$ All three items used in Eisenberg et al. (1991) were administered. Eisenberg et al. reported a Cronbach's alpha of .67. In the present study, Cronbach's alpha for these items was .50 (vs. .60 for the two items). Therefore, the two-item scale was used. The findings using the three-item scale were essentially identical to those reported. 
by experimenter bias. After completing the affective reasoning task, the money knowledge scale, and the sympathy scale (in a random order), each child was given $\$ 5$ in increments of four $\$ 1$ bills and four quarters as payment for participating in the study and asked to sign a receipt.

Children then watched a videotape (approximately $5 \mathrm{~min}$ long) of a girl about their age who has been burned. After a brief period of neutral activity (e.g., coloring at a table in her bedroom) in the film, there is an accident in which a girl is burned. The scene then shifts to the hospital where a concerned mother is seen talking to a friend on the phone; then, the girl is seen in bandages, walking using crutches, and recovering. The final scene shows the girl at school being teased because of her burn scars. On the basis of the task analysis both congruent and conflicting affective cues similar to those in the affective reasoning measure were identified in the video. For example, in the final scene, as the girl is having a pleasant and happy lunch (i.e., she is smiling) with a friend, she is teased about her scar by other children. Similar films have been found to be emotionally evocative and to elicit sympathy in children (e.g., Eisenberg et al., 1991; Strayer \& Schroeder, 1989).

After watching the video, children were told that the experimenter was a "member of a science club" that was "collecting money donations (for a local children's hospital burn unit) for children who have been burned ... like the one you saw in the film." Children were then asked to donate whatever amount of money they wished, including no money, to the burn unit. As they were told this, a donation box already containing some money (a fixed and known amount) was pointed out to the subject. To allow children to donate apparently anonymously, the experimenter then left the room after saying that she forgot something that she needed to get. The donation measure was simply scored as the amount of money the child placed into the donation box.

During debriefing, the children were asked open-ended questions concerning whether anything in the film had made them feel uncomfortable, whether they had seen this or a similar movie before, what they thought would be done with the donated money, whether they had talked about the study with their parents and what they had talked about, and whether they would be willing to avoid discussing the study with other children until the study was completed. ${ }^{3}$ Before leaving the experimental room the children were assured that the girl in the film was doing very well now and was fully recovered, and they were allowed to select a toy to keep (in addition to the money they had been given). No children were visibly upset at the time the session was over, and all agreed not to discuss the study with other children.

\section{Results}

Preliminary analyses revealed no significant main effects or interactions involving sex for any of the dispositional predictors or donation; therefore, sex was not included as a factor in the reported analyses. Preliminary analyses also indicated that the three dispositional predictors were not significantly intercorrelated (ranging from $r=-.16$ to .02 ). The means and standard deviations were as follows: affective reasoning $M=0.81$ and $S D=1.06$; sympathy $M=7.83$ and $S D=2.34$; money knowledge $M=6.44$ and $S D=2.93$; and donation $M=0.30$ and $S D=0.52$.

To assess the multiplicative relations of the dispositional variables to donation, a hierarchical multiple regression analysis was performed using donation as the criterion and the dispositional variables and all possible interactions as predictors. ${ }^{4}$ The scores on the predictors were centered before these analyses to eliminate the nonessential collinearity produced by the calculation of product terms (Aiken \& West, 1991). In this hierarchical multiple regression analysis the
Table 1

Results of the Hierarchical Multiple

Regression Analysis at Each Step

Variable entered $\quad$ Multiple $R^{2} \underline{\text { Standardized } \beta}$

Step 1

Affective reasoning

0.10

Sympathy

Money knowledge

Step 2

Affective reasoning (A)

Sympathy (B)

Money knowledge (C)

$\mathrm{A} \times \mathrm{B}$

$\mathrm{A} \times \mathrm{C}$

$\mathrm{B} \times \mathrm{C}$

Step 3

Affective reasoning (A)

Sympathy (B)

Money knowledge (C)

$\mathrm{A} \times \mathrm{B}$

$\mathrm{A} \times \mathrm{C}$

$\mathrm{B} \times \mathrm{C}$

$\mathrm{A} \times \mathrm{B} \times \mathrm{C}$

$.23 *$
$.22 *$

0.19

.03

.16

$.21 *$

.11

$.27^{*}$

.20

0.26

$\begin{array}{ll}-.03 & (-.03) \\ .26 * & \left(.25^{*}\right) \\ .27 * * & (.15) \\ .15 & (.15) \\ .33 * * & (.37 * *) \\ .15 & (.14) \\ .33 * * & (.37 * *)\end{array}$

Note. The coefficients in parentheses are for an analysis that also includes months of age as a predictor.

$* \mathrm{ps} \leq .05 .{ }^{*} \mathrm{p}<.01$.

three main effect vectors (affective reasoning, sympathy, and money knowledge) were entered on the first step, the three two-way interaction vectors were entered on the second step, and the three-way interaction vector was entered on the third step.

Table 1 presents the squared multiple correlation and the standardized partial regression coefficients for each step of the hierarchical multiple regression analysis. At the first step, the main effects accounted for $10 \%$ of the variance in donation, $F(3,82)=2.98, p$ $<.05$, with sympathy and money knowledge producing significant standardized partial regression coefficients. At the second step, the main effects and two-way interactions accounted for $19 \%$ of the variance in donation, $F(6,79)=3.04, . p<.01$, with money knowledge and the Affective Reasoning $\times$ Money Knowledge interaction producing significant standardized partial regression coefficients. Furthermore, the inclusion of the two-way interactions resulted in an additional $9 \%$ explained variance in donation, $F(3,79)=2.89, p<$ .05 . At the third step, the main effects, two-way interactions, and the three-way interaction accounted for $26 \%$ of the variance in donation,

${ }^{3}$ During debriefing, 5 children reported talking with their parents about donating to worthy causes. All children indicated a belief that the donations would go to the hospital burn unit and, with one exception, that they were free to decide how much to donate. One child was told by a parent to bring the money home. Analyses excluding these six cases produced essentially identical findings.

${ }^{4}$ Analyses using the reciprocal transformation of the donation and affective reasoning scores to correct for the skew in these distributions produced essentially identical findings. Furthermore, analyses of the residuals in the reported analyses revealed no unusually influential or out-lier cases. 
$F(7,78)=3.87, p<.0 \mathrm{I}$, with sympathy, money knowledge, the Affective Reasoning $\times$ Money Knowledge interaction, and the threeway interaction producing significant standardized partial regression coefficients. Moreover, as predicted, the inclusion of the three-way interaction resulted in an additional $7 \%$ explained variance in donation over and above the main effects and two-way interactions, $F(\mathrm{I}$, 78) $=7.35, p<.01$.

Figure 1 presents a graphic display of the significant threeway interaction using the procedures for examining interactions among continuous predictors as described by Aiken and West (1991). These procedures involve calculating simple regression lines at exemplar high and low values corresponding with one standard deviation above and below the mean for each predictor. Thus, the specific simple regression lines depicted in Figure 1 represent the nature of the three-way interaction at specific levels of the predictors. (A fully complete view of this interaction can only be represented by a threedimensional plane.) Tests of simple slopes for these four lines indicated that only the slope for the high affective reasoning-high sympathy regression line was significantly different from zero, $t(78)=4.97$, $p<.001$. That is, increases in money knowledge led to increases in donation only when the child was also high in affective reasoning and sympathy. Furthermore, as can be seen in Figure 1, those children who scored high in affective reasoning, sympathy, and knowledge about money donated considerably more than those who scored low on anyone or more of the dispositional variables.

Analyses also indicated that older children, relative to younger children, donated more money $(r=.23, p<.05)$ and scored higher in money knowledge $(r=.49, p<.001)$. However, age was not significantly related to affective reasoning $(r=-.08)$ or sympathy $(r=.04)$.

Table 1 also presents (in parentheses) the standardized partial regression coefficients for each of the dispositional predictors and interactions when months of age was also included as a main effect predictor. The only notable influence of the inclusion of age as a predictor was the substantial reduction of the standardized partial regression coefficient for the money knowledge main effect.

a
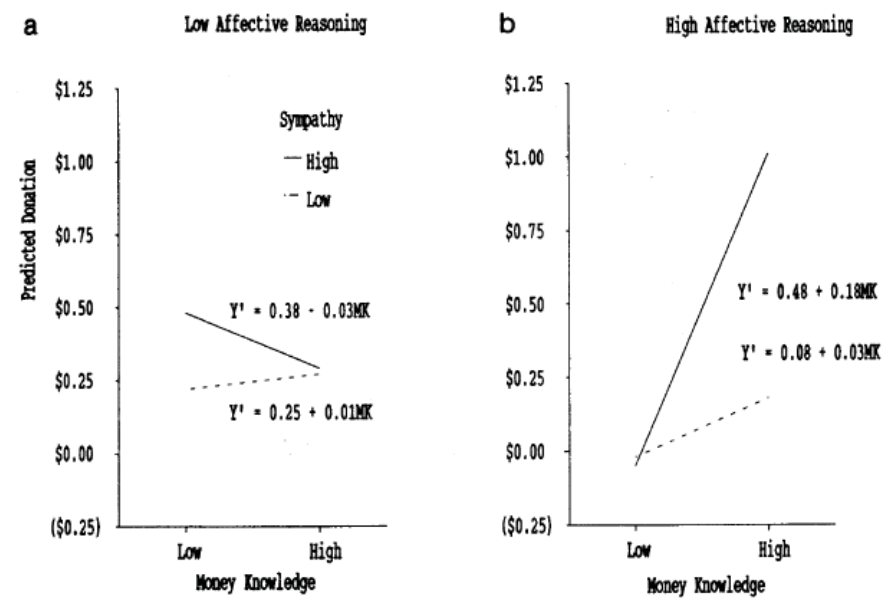

Figure 1. The three-way interaction involving low (Panel a) and high (Panel b) affective reasoning, sympathy, and money knowledge predicting the amount of money donated using the Aiken and West (1991) procedures for di splaying interactions among continuous variables ( $\mathrm{MK}=$ money knowledge).
If the age differences in donation were due to age differences in money knowledge, then the simultaneous entry of age and money knowledge into a multiple regression analysis predicting donations should produce an overall significant proportion of explained variance but nonsignificant standardized partial regression coefficients. This is because the standardized partial regression coefficients indicate the influence of the respective predictor after removing variance (i.e., statistically controlling) from the criterion variable associated with the other predictors included in the regression equation. This analysis revealed a significant overall regression equation, $F(2,83)$ $=3.23, p<.05$, and explained $7 \%$ of the variance in donations. However, the standardized partial regression coefficients for age (.15) and for money knowledge (.16) were both nonsignificant. Thus, the age differences in money knowledge accounted for the age differences in donations.

\section{Discussion}

As expected, the individual differences in donation behavior were a function of individual differences in the dispositional variables. Affective reasoning, sympathy, money knowledge, and the multiplicative relations of these variables accounted for $26 \%$ of the variance in donations. In addition, the utilization of a multiplicative dispositional model accounted for a substantially larger proportion (i.e., 2.6 times as much) of the variance in donations than a simple additive model including only main effects. Furthermore, the age differences in donations may be a function of age differences in money knowledge. Overall, the present findings help provide a more thorough understanding of individual and developmental differences in prosocial behavior and have several important implications.

The present findings demonstrate the possibility that a given prosocial behavior may have multiple dispositional antecedents that function interactively to produce behavior. As expected, children who scored high in affective reasoning, sympathy, and money knowledge donated the most, and scoring low on any subset of these dispositional predictors resulted in a larger reduction in donations than would be expected by a simple additive model. Consider, for example, a comparison of two hypothetical children: Child A, who scores high (i.e., one standard deviation above the mean) in affective reasoning, sympathy, and money knowledge, and Child $\mathrm{B}$, who scores high in affective reasoning and money knowledge but low (i.e., one standard deviation below the mean) in sympathy. A simple additive model based on a regression equation in which only main effect predictors were entered would lead to predicted donations of $\$ 0.56$ (11.2\% of the available $\$ 5)$ for Child A and $\$ 0.34$ (6.8\%) for Child B. In contrast, the multiplicative model would lead to predicted donations of $\$ 1.01$ (20.2\% of the available $\$ 5$ ) for Child A and $\$ 0.18$ (3.6\%) for Child B. Thus, in the present study, scoring low on only sympathy would lead to an expected reduction in donation of $\$ 0.22$ (a $4.4 \%$ difference) in the simple additive model versus $\$ 0.87$ (a $17.4 \%$ difference) in the multiplicative dispositional model.

By not examining the multiplicative influences of dispositional antecedents, previous research may have underestimated the magnitude, and importance, of dispositional influences on prosocial behavior. In the present study, a simple additive model accounted for only 
$10 \%$ of the variance in donations, whereas the multiplicative dispositional model accounted for $26 \%$ of the variance. In addition, the simple additive model, or single predictor model, would have incorrectly led to the conclusion that affective reasoning was not an important dispositional variable in explaining variance in donations. It is also likely that the examination of multiplicative dispositional models may enhance the explanation of variance in behaviors other than prosocial behaviors. Although a number of researchers have considered Person $\times$ Situation interactions in an attempt to explain a greater proportion of the variance in a wide range of behaviors (e.g., Bem \& Allen, 1974; Bem \& Funder, 1978; Funder \& Colvin, 1991; Kenrick \& Funder 1988; Magnusson \& Endler, 1977; Zuckerman, Bernieri, Koestner, \& Rosenthal, 1989), there has been relatively little consideration of the multiplicative influence of dispositional variables.

Another implication of the present findings is that it may take a conglomerate of dispositional variables to stimulate a given prosocial behavior. Although it may not be clear how and whether such a conglomerate differs from a global personality variable as described by Funder (1991), a conglomerate is quite different from an aggregate of dispositional variables. A conglomerate of dispositional variables is a mixture of specific dispositional variables existing together while maintaining their unique qualities. When variables are aggregated they are simply summed together without regard for their unique qualities. If indeed, a given prosocial behavior has multiple dispositional antecedents that are causally related to that prosocial behavior in a multiplicative manner, then aggregating the multiple dispositional antecedents would underestimate the causal influence of the dispositional antecedents.

The present findings are also consistent with the suggestion that there may be situation-specific dispositional antecedents of specific prosocial behaviors. The dispositional predictors used in this study were selected on the basis of a task analysis of the specific prosocial behavior opportunity. A prosocial behavior different from that investigated in this study may have, and pull for (cf. Snyder \& Ickes, 1985), a different set of dispositional antecedents. For example, Carlo et al. (1991) demonstrated that affective reasoning was related to helping in a situation that contained incongruent affective cues, but not related to helping in a situation that contained only congruent cues. Furthermore, if different prosocial behaviors have different dispositional antecedents, then aggregating prosocial behaviors would also underestimate the magnitude, and importance, of dispositional influences.

Finally, these findings also have implications for researchers' understanding of prosocial development. Developmental changes in the task-relevant dispositional antecedents could explain the developmental changes in a specific prosocial behavior. Furthermore, developmental changes in situation-specific dispositional antecedents could explain the variability in the pattern of age differences across prosocial behaviors (Eisenberg, 1986). For example, there are substantial developmental changes in cooperative resource allocations around 5 years of age (Chao et al., 1986), monetary donations in the 6-8-year age range (this investigation), sharing an object in a fixed time interval around 8 years of age (Knight et al., 1993), and proportional equity resource distributions in early adolescence (Hook \& Cook, 1979). The occurrence of these prosocial behaviors at quite different ages may, in part, be due to individual differences in the ac- quisition of the task-relevant dispositional qualities (i.e., mathematical operations skills, knowledge of the units and values of money, temporal monitoring abilities, and proportional thought abilities, respectively). Although the relations among these specific sociocognitive dispositional qualities and prosocial behaviors could be the spurious result of general achievement or intelligence differences, this seems unlikely given the discriminant relations noted earlier (Carlo et al., 1991) and given the low positive correlations between intelligence and prosocial behavior that are very often nonsignificant (see Eisenberg \& Mussen, 1989; Radke-Yarrow, Zahn-Waxler, \& Chapman, 1983).

\section{References}

Aiken, L. S., \& West, S. G. (1991). Multiple regression: Testing and interpreting interactions. Newbury Park, CA: Sage.

Bem, D. J., \& Allen, A. (1974). On predicting some of the people some of the time: The search for cross-situational consistencies in behavior. Psychological Review, 81, 506-520.

Bem, D. J., \& Funder, D. C. (1978). Predicting more of the people more

of the time: Assessing the personality of situations. Psychological Review, 85 , 485-501.

Berti, A. E., \& Bombi, A. S. (1981). The development of the concept of money and its value: A longitudinal study. Child Development, 52, 11791182 .

Brady, J. E., Newcomb, A. F., \& Hartup, W. W. (1983). Context and companion's behavior as determinants of cooperation and competition in school-age children. Journal of Experimental Child Psychology, 36, 396-412.

Bryant, B. K. (1982). An index of empathy for children and adolescents. Child Development, 53, 413-425.

Carlo, G., Knight, G. P., Eisenberg, N., \& Rotenberg, K. J. (1991). Cognitive processes and prosocial behaviors among children: The role of cognitive attributions and reconciliations. Developmental Psychology, 27, 456-461.

Chao, C.-C., Knight, G. P., \& Dubro, A. F. (1986). Information processing and age differences in social decision-making. Developmental Psychology, 22, 500-508.

Davis, M. H. (1983). Measuring individual differences in empathy: Evidence for a multidimensional approach. Journal of Personality and Social Psychology, 44, 113-126.

Eisenberg, N. (1986). Altruistic emotion. cognition and behavior. Hillsdale, NJ: Erlbaum.

Eisenberg, N., Fabes, R. A., Schaller, M., Carlo, G., \& Miller, P. A. (1991). The relations of parental characteristics and practices to children's vicarious emotional responding. Child Development, 62, 1393-1408.

Eisenberg, N., \& Miller, P. A. (1987). The relation of empathy to prosocial and related behaviors. Psychological Bulletin, 101, 91-119.

Eisenberg, N., \& Mussen, P. H. (1989). The roots of prosocial behavior in children. Cambridge, England: Cambridge University Press.

Funder, D. C. (1991). Global traits: A neo-Allportian approach to personality. Psychological Science, 2, 31-39.

Funder, D. C., \& Colvin, R. (1991). Explorations in behavioral consistency: Properties of persons, situations, and behaviors. Journal of Personality and Social Psychology, 60, 773-794. 
Hook, J. G., \& Cook, T. D. (1979). Equity theory and the cognitive ability of children. Psychological Bulletin, 86, 429-445.

Iannotti, R. J. (1978). Effect of role-taking experiences on role-taking, empathy, altruism, and aggression. Developmental Psychology, 14, 119-124.

Kenrick, D. T., \& Funder, D. C. (1988). Profiting from controversy: Lessons from the person-situation debate. American Psychologist, 43, 23-34.

Knight, G. P., Bohlmeyer, E. M., Stewart, H. S., \& Harris, J. D. (1993). Age differences in temporal monitoring and equal sharing in a fixed-duration sharing task. British Journal of Developmental Psychology, 11, 143158 .

Magnusson, D., \& Endler, N. S. (Eds.). (1977). Personality at the crossroads: Current issues in interactional psychology. Hillsdale, NJ: Erlbaum.

Radke-Yarrow, M., Zahn-Waxler, C., \& Chapman, M. (1983). Prosocial dispositions and behavior. In P. Mussen (Series Ed.) \& E. M. Hetherington (Vol. Ed.), Manual of child psychology: Vol. 4. Socialization, personality, and social development (pp. 469-545). New York: Wiley.
Snyder, M., \& Ickes, W. (1985). Personality and social behavior. In G. Lindzey \& E. Aronson (Eds.), Handbook of social psychology (3rd ed., pp. 883-948). New York: Random House.

Staub, E. (1978). Positive social behavior and morality: Social and personal influences. San Diego, CA: Academic Press.

Strayer, J., \& Schroeder, M. (1989). Children's helping strategies: Influences of emotion, empathy, and age. In N. Eisenberg (Ed.), New directions for child development: Empathy and related emotional responses (pp. 85105). San Francisco: Jossey-Bass.

Underwood, B., \& Moore, B. (1982). Perspective-taking and altruism. Psychological Bulletin, 91, 143-173.

Zuckerman, M., Bernieri, F., Koestner, R., \& Rosenthal, R. (1989). To predict some of the people some of the time: In search of moderators. Journal of Personality and Social Psychology, 57, 279-293.

Submitted January 1993; revised April 1993; accepted June 1993. 